\title{
Financial Inclusion: Opportunities, Issues and Challenges
}

\author{
George Varghese, Lakshmi Viswanathan \\ Institute for Financial Management and Research (IFMR), Sri City, Chittoor (Dist), India \\ Email: george.v@ifmr.ac.in, lakshmiviswanathan15@gmail.com
}

How to cite this paper: Varghese, G. and Viswanathan, L. (2018) Financial Inclusion: Opportunities, Issues and Challenges. Theoretical Economics Letters, 8, 1935-1942. https://doi.org/10.4236/tel.2018.811126

Received: April 11, 2018

Accepted: July 20, 2018

Published: July 23, 2018

Copyright $\odot 2018$ by authors and Scientific Research Publishing Inc. This work is licensed under the Creative Commons Attribution International License (CC BY 4.0).

http://creativecommons.org/licenses/by/4.0/

\begin{abstract}
An all-inclusive financial system is essential for a nation as it augments efficiency and welfare by providing scope for secure and safe saving practices and by facilitating a wide range of improved financial services. The focus of the present study is on identifying the opportunities, issues, and challenges of financial inclusion in India.
\end{abstract}

\section{Keywords}

Financial Inclusion, Financial Exclusion, Financial Services, Financial Literacy, Poverty

\section{Introduction}

Financial inclusion is a fundamental keystone of socio-economic development. It has been a policy goal of high priority in India for decades. It is an important policy option which aims at reducing poverty and minimizing social as well as financial exclusion, thereby enhancing the inclusive growth process. Though there has been considerable progress in the process of inclusion over the past few years, India remains along way from attaining universal financial inclusion.

The term financial inclusion is defined as the process of ensuring timely access to financial services and adequate credit where needed by vulnerable groups such as the weaker sections and low-income groups at an affordable cost [1]. However, it is perceived differently under different contexts. It can be viewed as a process of enabling access to credit, improving banking services or as a process of developing social and economic infrastructure available to the public. In short, financial inclusion is not only about money and savings but about directly eradicating the state of social exclusion existing in the economy.

The Government of India and the central bank have been focussing on finan- 
cial inclusion through increasing financial literacy among the under privileged and by strengthening credit delivery mechanisms to targeted sections. To this end, the increase in financial literacy has not only increased the number of bank accounts, but also significantly reduced the account dormancy. Further, financial inclusion penetrated significantly into India's traditionally marginalized communities, reducing the gaps between rural and urban, below and above poverty populations and between men and women. Their concerted efforts over the last five decades include nationalization of banks, the creation of well-knit branch network of scheduled commercial banks, co-operatives and regional rural banks, promotion of priority sector lending, the introduction of lead bank scheme, the formation of self-help groups and provision of zero balance BSBD accounts.

The Pradhan Mantri Jan-DhanYojana (PMJDY), a people's welfare scheme launched by Prime Minister Narendra Modi in 2014 has a decisive impact on India's stride in achieving financial inclusion over the last few years and has been extremely effective in bringing the socially excluded within the preview of the banking system. The program is an initiative to ensure that at least one registered bank account was available for every household nationwide. The FII surveys show a steady increase in the number of adults registered bank accounts post the launch of PMJDY in August 2014. An 18 percent increase in the percentage of population with a registered bank account for the period between 2013 and 2015 demonstrates the success of the program in backing an all-inclusive economic growth. Going forward, the success of financial inclusion greatly depends on expanding the scope of PMJDY to include all individuals in the population (above certain age) rather than only one account per household.

Given the size and diverse nature of the financially excluded population in India, the responsibility of accelerating inclusive growth lies equally on each stakeholder: the government, private and public banks and the social sector. The process of inclusive growth is not free of issues and challenges. But it also opens new windows of opportunities for socio-economic development. The rest of the chapter is organized into 4 sections. Section II is about the opportunities for development. Section III describes issues and challenges related to the process of financial inclusion. Section IV suggests some ways to improve the process of inclusive growth and Section V consists of concluding remarks.

\section{Opportunities}

Financial inclusion provides a unique opportunity to construct a sustainable financial system. The opportunities for the government as well the financial service providers are plenty. It accelerates growth in the real sector and triggers overall economic development.

To begin with, the micro-insurance could be an important mechanism for mitigating risk. If the regulators are able to induce trust regarding the product and reduce liquidity constraints, this could help the rural population to ease their vulnerability to risk [2]. The micro-finance institutions and self-help group 
movements improved credit availability in rural areas. As a result, there is an increase in agricultural productivity and other rural activities that generate income. The increase in income leads to higher consumption, higher saving and higher investment. The poverty levels are declining and are bound to decline further if this trend continues [3]. The reduced poverty level will accelerate the rate of integration with the formal banking system. Access to finance will further attract global market players thereby increasing business and employment opportunities.

The introduction of remittance corridors for the migrant population is an enormous opportunity for the migrants from rural areas, to exercise easy and cheap remittance facilities. As of now, migrants are not adequately covered and are facing difficulties in opening bank accounts. Further, it opens an opportunity for the unbanked/underserved community to raise their levels of financial literacy and bring about a greater awareness about their rights. Financial inclusion in a holistic sense provides not only safe savings but also offer many other allied services like insurance cover, entrepreneurial loans, payments and settlement facilities etc.

There are plenty of opportunities for financial institutions as well. Though the Indian banking credit relished a significant growth since 2003, credit penetration is still below global benchmark. By aiding the inclusive growth process, banks and other financial institutions have greater scope to widen their customer base and improve their performance. A large resource base can help reduce the transaction cost, thereby improving the overall efficiency of the system. Further, with the help of simpler KYC norms and UID, banking process can become easier, which will then help to reduce the cash and non-cash costs. Banks and other financial institutions can achieve low-cost solutions also by partnering with non-industry organizations and NGOs to perform certain functions. Given their deeper understanding of the local communities, the risk of default can be reduced by integrating with them.

Banks need to introduce low-cost, customer-oriented innovative products to turn the process of financial inclusion to the next big business opportunity. It is an opportunity for private sector banks to expand their base to the rural areas. A strategic expansion in technology can be of advantage as it enables easier and accurate banking process. For instance, mobile money reduces households' transaction costs and improves their ability to share risk [4]. In rural India, there were 323.27 million mobile subscribers as of March 2012 [5]. To explore such opportunities, RBI has constituted a committee headed by B. Sambamurthy to explore the options including the feasibility of using encrypted SMS-based funds transfer.

The combination of IT and IT-enabled services have emerged as a sustainable solution for greater financial inclusion. This will minimize the need for setting up physical branches at all locations. It allows the servicing banks to improve efficiency and provides for use of multiple channels to work together as an inte- 
grated system. Banks have to make effective use of information and communication technology (ICT) to provide door step delivery of financial services. Enabling more technologically trained banking correspondents for doorstep banking in rural areas will enhance the confidence of consumers and make the process convenient. An improved version of the $\mathrm{BC}$ the model will definitely help as the older model has a success story to tell (Figure 1). Banking on the reliability and efficiency of trained business correspondents, the number of BC's employed by the banks nationwide has increased 78 percent in just three years (2010 through 2013).

It is wise to tie up with telecommunication companies to deliver financial, health and other development services as the technology has the potential to address the issues of outreach and credit delivery in rural areas. Financial inclusion provides opportunities to the banking sector to cut across various layers' of people, regions, gender, and income and encourage the public to inculcate banking habit.

\section{Issues and Challenges}

On addressing the issues related to financial inclusion, it is extremely important to take a holistic approach addressing both supply and demand-side factors. The large size of the unbanked population spread across vast geographies, limited access to credit, low skill, low productivity and vulnerability to the risk of small and marginal farmers, rural landless and urban poor and lack of financial and technological literacy are some of the demand side issues.

Among the supply side challenges, the most cited one is the reluctance of financial institutions to serve small value and unprofitable customers with irregular income. That is to say, banks perceive inclusion as an obligation rather than a business opportunity. High loan default rates during the past add to the severity of this constraint. Besides, outlays of different schemes meant for the rural and



Figure 1. Banking correspondents. 
urban poor did not translate into outcomes due to the poor delivery mechanism.

The urban poor does not fully utilize the financial services as the transaction costs are unaffordable to them. Another factor preventing them from accessing formal financial institutions are the requirement of various document proof. The poor generally lack documents such as income certificate, birth certificate, address proof etc. Nevertheless, the opening of an account alone does not assure integration with formal economy. It requires one to involve in income generating economic activities with monetary transactions. The existence of dormant accounts is the major criticism against the Pradhan Mantra Jan Dhan Yojna (2014). It is noteworthy that the percentage of dormant accounts with zero balance is highest in the case of Regional Rural Banks (refer Table 1).

Another barrier to successful implementation of financial inclusion plan is the highly restrictive nature of banking correspondent (BC) model. The model failed due to various reasons, like the improper and inadequate use of technology, the absence of reach and coverage, lack of proper infrastructure etc. The core issue is the absence of any incentive for BC's mainly financial stability. The BCs are also not completely aware of the significance of reputational risk of the bank and act irresponsibly on many occasions. Thus there is a great need of organizing regular training programs for BCs. Technological training is also important for better delivery of services.

Although SHG-Bank linkage model was proclaimed successful in rural areas, its reach across the nation is highly uneven (refer Table 2). Additionally, it was observed that the SHGs were unable to procure loans from banks even after a year of formation and group activities (refer Figure 2). Figure 2 is an excerpt

Table 1. PMJDY accounts opened as on 8.6.2016 (Figures in crores).

\begin{tabular}{ccccc}
\hline Bank Name & Rural & Urban & Total & Zero balance accounts (\%) \\
\hline Public Sector Banks & 9.70 & 7.65 & 17.35 & 25.89 \\
Private Sector Banks & 3.37 & 0.55 & 3.92 & 21.81 \\
Regional Rural Banks & 0.50 & 0.31 & 0.81 & 37.69 \\
Total & 13.57 & 8.51 & 22.08 & 25.60 \\
\hline
\end{tabular}

Source: pmjdy.gov.in.

Table 2. Region-wise spread of SHGs.

\begin{tabular}{ccc}
\hline Region & No: of SHGs & Percentage of total \\
\hline Northern & 372772 & 5.00 \\
North-eastern & 324739 & 4.35 \\
Eastern & 1527618 & 20.47 \\
Central & 786436 & 10.14 \\
Western & 960921 & 12.88 \\
Southern & 3489460 & 46.76 \\
\hline
\end{tabular}

Source: Status of Microfinance in India (2010-11): A NABARD publication. 


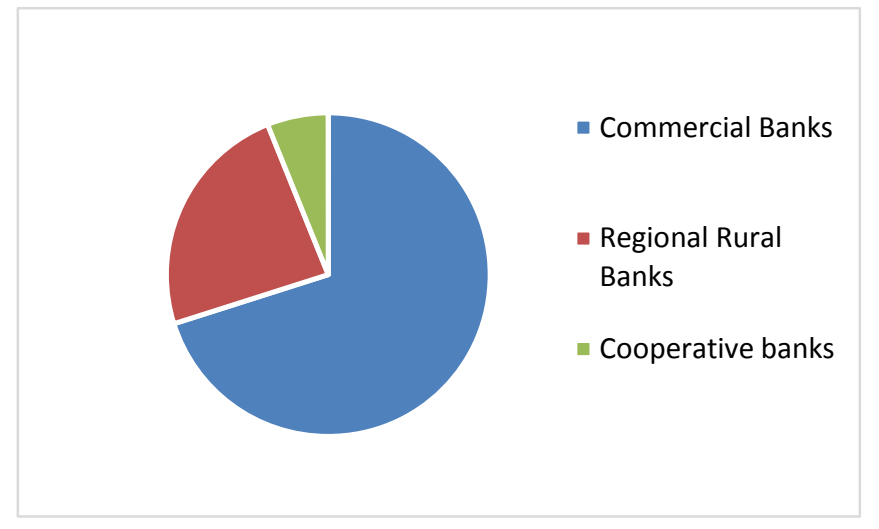

Figure 2. Bank loans outstanding against SHGs. Source: Status of Microfinance in India (2010-11): A NABARD publication.

from a larger study entitled 'Status of Microfinance in India (2010-11) which is a part of NABARD publication. Interested readers can refer the same for a broader perspective on the SHG-Bank linkage model.

The rural population relies mostly on informal sector for availing finance at exorbitant rates. They get caught up in the vicious circle of poverty, debt and debt repayment and hence fail to access any formal financial services. Lack of financial literacy is the major reason behind this. The absence of basic education prevents people from following even simpler information related to financial inclusion. They remain ignorant even about basic products like insurance, bank accounts, cheque facilities etc. This ignorance poses a challenge for policy makers in facilitating financial services through the use of technology in rural and semi-urban areas.

\section{Ways Ahead}

Substantial investments in social and physical infrastructure as well as in financial literacy, need-based products, and services along with innovative delivery mechanism are essential to enable the economy in achieving inclusive growth. Investment in physical infrastructure will lead to the generation of employment, improve efficiency, reduce cost and thus will improve the overall standard of living. Investment in financial literacy is considered as the most crucial step without which any policy action with regard to financial inclusion will remain futile. It is the need of the hour to educate the target section about the available services and to create an awareness about their rights.

Banks need to focus more on introducing tailor-made services and deliver it through a better and effective mechanism. The credit disbursement should be made more flexible in order to attract the consumers who are used to informal sources of credit. Encouraging NGOs and MFIs to participate in this process will help identify default risk as they work closely with the target population. Provision of general credit card (GCC) or a limited OD against no-frills account will increase the access of credit. It will be ideal if affordable insurance and remit- 
tance facilities are encompassed in the same plan. Banks should extend the service of BCs to include Kirana shops and other local enterprises. At the same time, BCs need to be properly incentivized and monitored by the banks. Leveraging modern technology, eliminating multiple layers of governance, easing procedures and better participatory role by benefactors can help in building a better delivery mechanism that provides greater confidence and security.

An affordable and accessible platform to avail the services should be provided. Post offices could play a proactive role in inclusive growth in areas where there are no banks and other formal financial institutions. A low-cost solution, based on mobile technology can be a good platform to deliver financial services. Reducing the risk of agent misconduct, investing in audit studies, conducting risk management assessments, usage of new and improved technologies to provide information, and keeping the consumers updated of the changes are some of the popular and effective strategies that India could adopt from countries like across Asia and Africa in our journey to an all-inclusive economic growth.

There is a strong need to restructure the financial system, particularly the services available for the rural population. A coordinated drive for financial inclusion involving educational institutions is necessary to promote financial literacy. Regular surveys should be conducted in villages to understand financial needs of the people and to check whether the products available are actually utilized by them and meets their expectations. RBI should allow telecom service providers to provide enhanced banking products at affordable prices. Giving authorization to microfinance as well as non-banking financial organizations to perform limited mainstream financial services in remote areas can help improve the reach of the program. These measures, if effectively implemented guarantees to accelerate the process of inclusive growth.

\section{Conclusion}

Financial inclusion is not a short-term goal. It is a progressive initiative, which will evolve itself over a period of time. The short-term opportunities should be made use of and the shortcomings should be duly corrected in order to accelerate the process of inclusion. The opportunities and challenges provide useful insights regarding innovative ways of economic value addition, which help the $\mathrm{Na}$ tion reach a growth trajectory that is sustainable. Therefore, policymakers should focus on developing policies considering a sustainable banking services delivery model and need-based products for rural and urban consumers.

\section{References}

[1] Rangarajan Committee (2008) Report of the Committee on Financial Inclusion. The Government of India.

[2] Matul, M., Dalal, A., De Bock, O. and Gelade, W. (2013) Why People Do Not Buy Microinsurance and What We Can Do About It. Briefing Note 17, Microinsurance Innovation Facility, Geneva.

[3] Burgess, R., Pande, R. and Wong, G. (2005) Banking for the Poor: Evidence from 
India. Journal of the European Economic Association, 3, 268-278.

https://doi.org/10.1162/jeea.2005.3.2-3.268

[4] Blumenstock, J., Eagle, N. and Fafchamps, M. (2011) Charity and Reciprocity in Mobile Phone-Based Giving: Evidence from Rwanda.

[5] https://www.trai.gov.in/content/annual_reports.aspx 